\title{
Awareness of Post - Exposure Prophylaxis Guidelines against Occupational Exposure to HIV Among Post Graduate Residents at Mangalore, India
}

\author{
Saraswati Viswanathan', Rashmi Jain², M Prabha Adhikari ${ }^{3}$, Animesh Jain ${ }^{4, *}$ \\ ${ }^{1}$ Senior Resident, Department of Orthopaedics, Kasturba Medical College (Manipal University), Manipal, India. \\ ${ }^{2}$ Assistant Professor, Department of Ophthalmology, Yenepoya Medical College, Yenepoya University, Deralakatte, Mangalore, India. \\ ${ }^{3}$ Professor, Department of Medicine, Kasturba Medical College (Manipal University), Mangalore, India. \\ ${ }^{4}$ Associate Professor, Department of Community Medicine, Kasturba Medical College (Manipal University), Mangalore, India.
}

\section{A B STR A C T}

\begin{abstract}
Background: Health care workers (HCWs) are regularly exposed to blood, and other body fluids which make them prone to a risk of acquiring the infection. Despite following 'universal precautions', accidental exposure may occur while performing invasive procedures and handling high risk fluids. Objectives: (a) To assess the awareness of post exposure prophylaxis (PEP) in case of needle-stick injury from confirmed or suspected source of HIV amongst l-year postgraduate residents of Kasturba Medical College \& Manipal College of Dental Sciences, Mangalore, India. (b) To educate them about the post-exposure prophylaxis guidelines against occupational exposure to HIV. Methodology: This is a cross sectional study among 85 postgraduate residents based on response to structured questionnaire. Results were analyzed and tabulated using National AIDS Control Organization Guidelines as reference standard for comparison. Results: Nineteen respondents $(22 \%)$ were aware of the true risk of transmission. About half of the respondents identified all the high risk fluids correctly. Twenty-five respondents $(29 \%)$ knew whom to contact immediately after accidental exposure while only 20respondents $(23 \%)$ knew that washing with soap and water was the initial measure. Though half of the respondents knew that prophylaxis should be initiated within 1hour of injury, a mere $30 \%$ knew the correct duration of PEP. $42 \%$ respondents were aware of the availability of drugs and only $28 \%$ knew the approximate cost of therapy. Conclusion: There is a considerable lack of awareness among the medical and dental postgraduate residents about the PEP against accidental exposure to HIV suggesting a need for training and awareness programmes to improve the awareness.
\end{abstract}

Key words: Post exposure prophylaxis, HIV, occupational exposure, post-graduate residents, Mangalore, questionnaire.

\section{INTRODUCTION}

The health care workers (HCWs) are regularly exposed to blood, tissue or other body fluids which render them at risk of acquiring the human immunodeficiency virus (HIV) infection. The extent of risk to HCWs depends on the prevalence of infection in patient population and the

*Address for correspondence:

Dr Animesh Jain, MD

Department of Community Medicine,

Kasturba Medical College (Manipal University),

Light House Hill Road, Mangalore - 575001 INDIA.

Phone: +91 $8242422271 / 2423452$ ext 5560

Mobile: +919845032334

Fax: +91 8242428183

E-mail:animesh_j@yahoo.com; animesh.jain@manipal.edu

DOI: 10.5530/ijmedph.2.2011.13 duration of period of risk. It is estimated that a surgeon working in high prevalence American or European inner city area over a 30 year career has roughly a 1:800 chance of acquiring HIV infection. In Africa where prevalence of HIV infection is much higher and the risk of infection in blood products is also higher, a similar career risk has been estimated to be as high as 1:4. ${ }^{1}$ The sero-prevalence rates of $\mathrm{HIV}$ in India vary widely - ranging from $0.3 \%$ to $7.2 \%$ depending on the geographic area and demographic characteristics. ${ }^{2}$ Based on sentinel surveillance, the prevalence rates of HIV in adult population can be classified into high, moderate, and low prevalence states. ${ }^{3}$ The southern Indian state of Karnataka is one among the six states with high prevalence rates. ${ }^{3,4}$

The HIV status of a majority of patients is unknown at the time of initial presentation to the hospital. Despite following 'Universal precautions', the HCWs may get 
accidentally exposed to HIV while performing invasive procedures and/or handling high risk fluids. Most exposures do not result in infection ${ }^{5}$ but the risk of infection varies with the type of exposure, the amount of blood involved and the amount of virus in the patient's blood and whether the post exposure prophylaxis (PEP) was taken within recommended time. ${ }^{6,7}$ It has been shown that over one third of exposed HCWs do not report needlestick injuries. ${ }^{8}$

The National AIDS Control Organization (NACO) has formulated certain guidelines for post exposure prophylaxis (PEP) to prevent transmission of disease among HCWs in India. ${ }^{9,10}$ The postgraduates and residents are the future consultants and medical teachers so it is imperative that they are aware of the risk of transmission as well as the guidelines so as to educate their junior colleagues, students and others. There is a paucity of data pertaining to the awareness about PEP among MBBS and BDS graduates and postgraduate residents. This study was conducted amongst first year postgraduate residents of Kasturba Medical College, Mangalore and Manipal College of Dental Sciences, Mangalore to determine their knowledge and awareness regarding risk of transmission and PEP guidelines in case of accidental needle-stick injury from confirmed or suspected source of HIV and also to educate them about these guidelines.

\section{METHODOLOGY}

This cross sectional study was conducted during a day long medical postgraduates' orientation training programme. All the participants had been working in the hospital outpatients department and/or wards or laboratory for the four months prior to the day of study. Questions in the proforma were related to risk of transmission, identification of high risk fluids, drugs, cost and procedure to be adopted for PEP. A structured nine - item anonymous questionnaire was given to all the 85 postgraduates present at the beginning of the first session. The questionnaire was administered to the participants by one of the first two authors at the beginning of the Orientation programme and they were allowed 15 minutes time exclusively to fill up the questionnaire after which it was promptly collected. Care was taken to ensure that there was no discussion or copying among the respondents while answering the questionnaire. Towards the end of the day a session on PEP guidelines was organized and an expert in the field delivered a talk and answered the queries of the participants.

The data collected was analysed and tabulated. The NACO guidelines ${ }^{9}$ were taken as reference standard for comparison during the analysis.

\section{RESULTS}

All the respondents approached consented to answer the questionnaire yielding a response rate of 100 per cent. Out of the eighty five respondents, 58 (68.23\%) were males, $25(29.41 \%)$ females and there were two forms without any mention of the gender. Twenty three $(27.06 \%)$ respondents belonged to $20-24 \mathrm{yr}$ age group, $50(58.82 \%)$ to $25-29$ years, $6(7.06 \%)$ belonged to $30-34$ years age group and a further $6(7.06 \%)$ had not mentioned their age.

We grouped the respondents into four groups depending on the risk of contact with potentially infected fluids/ tissues [Table 1]. The postgraduates from the departments

\begin{tabular}{|c|c|c|c|}
\hline Group & Departments & Risk of contact with source of HIV & $\begin{array}{l}\text { No. of respondents } \\
\text { (Percentage) }\end{array}$ \\
\hline$I$ & $\begin{array}{l}\text { Anatomy } \\
\text { Pharmacology } \\
\text { Physiology }\end{array}$ & Uncommon/Rare & $5(5.95)$ \\
\hline II & $\begin{array}{l}\text { Biochemistry } \\
\text { Microbiology } \\
\text { Pathology }\end{array}$ & $\begin{array}{l}\text { Frequent contact with high risk fluid and } \\
\text { specimens }\end{array}$ & $11(13.1)$ \\
\hline III & $\begin{array}{l}\text { Anaesthesia } \\
\text { ENT } \\
\text { Medicine } \\
\text { Ophthalmology } \\
\text { Orthopaedics } \\
\text { Paediatrics } \\
\text { Skin and STD } \\
\text { Surgery }\end{array}$ & $\begin{array}{l}\text { Frequent contact with patients whose HIV status } \\
\text { is generally not known and high risk fluids }\end{array}$ & $56(66.7)$ \\
\hline \multirow[t]{2}{*}{ IV Dental } & $\begin{array}{l}\text { Endodontics } \\
\text { Oral pathology } \\
\text { Oral Surgery } \\
\text { Orthodontics }\end{array}$ & $\begin{array}{l}\text { Frequent contact with patients whose HIV status } \\
\text { is generally not known }\end{array}$ & $12(14.28)$ \\
\hline & & Total & 84 \\
\hline
\end{tabular}

Note: One respondent had not mentioned the department. 
of Anatomy, Physiology and Pharmacology hardly had any contact with potential infective material so they formed the group I. Group II consisted of postgraduates from departments which receive specimens for laboratory diagnosis. These do not have direct contact with patients but have a risk due to their exposure to the specimens and fluids which may be infected. All the clinical departments were grouped as Group III. The dentists were grouped together into Group IV.

\section{Risk of transmission}

The risk of transmission is estimated to be $0.3 \%$ (i.e. 3 per 1000 injuries) $\{95 \%$ confidence interval CI-0.2 to $0.5 \%\}$ in case of injury with hollow needle. ${ }^{(6,9,11,12)}$ Only nineteen respondents $(22.35 \%)$ were aware of this risk. Fourteen (25\%) of the 56 PG residents from group III knew the correct answer while none of the dental PG residents were aware of this. Eleven respondents (12.9\%) grossly over estimated the risk in the range of $60-100 \%$ whereas $15(17.6 \%)$ underestimated the risk.

\section{Identification of high risk fluids}

Pleural, peritoneal, synovial and cerebrospinal (CSF) fluids are high risk fluids for transmitting HIV as compared to urine, saliva, faeces and vomitus. ${ }^{(9,12,13)}$ Forty three respondents $(50.6 \%)$ identified all high risk fluids correctly. This number includes four from group I ( $80 \%$ of group total), six from group II (54.5\% of group total), 29 from group III (51.7\% of group total), and four from group IV (33.3\% of group total).

Twenty three respondents wrongly considered saliva as a high risk fluid; five (21.7\%) among these were dental PG residents (group IV). Further analysis showed that 41.7\% of dental PG residents (5 among 12) considered saliva as a high risk fluid. Five respondents $(5.9 \%)$ had even thought urine to be a high risk fluid.

\section{Whom to contact first?}

Most hospitals have a protocol to be followed in case of occupational exposure or needle stick injury. At our hospital, a Physician from Medicine Unit I (Infection Control) has to be contacted in the event of accidental exposure. Twenty five respondents $(29.4 \%) \mathrm{knew}$ whom to contact in our set up and 31 (36.5\%) gave various answers ranging from $\mathrm{CMO}$, to Department of Microbiology to senior staff and even the head of the department and the head of the institution. Twenty nine respondents $(34.1 \%)$ chose not to answer this question.

\section{First aid measures}

First aid procedure mainly involves washing with soap and water. $^{(9,14)}$ Only $20(23.5 \%)$ knew the appropriate first aid procedure. Nine respondents $(10.6 \%)$ answered active bleeding from the site while $49(57.6 \%)$ said cleaning with antiseptics was the first aid measure. Antiseptics to be used as stated by the respondents included spirit, betadine, sodium hypochlorite, chlorheximide, and formalin. One respondent even mentioned intra-venous Zidovudine as the first aid measure. On analyzing the data group-wise, it was found that none of the PGs from group I had any idea of the first aid measures.

\section{When to initiate PEP?}

Post exposure prophylaxis should be initiated as soon as possible and preferably within two hours of the needlestick injury. ${ }^{(9,13,14)}$ Of all the respondents, only $43(50.5 \%)$ answered this question correctly while 2 respondents $(2.3 \%)$ said that PEP should be initiated within 4 hours of exposure. Ten respondents $(11.8 \%)$ did not answer this question.

\section{Drugs used for PEP}

NACO guidelines state that PEP should consist of a combination of two nucleoside analogue reverse transcriptase inhibitors (Zidovudine and Lamivudine). In extended drug regimen (for high risk exposure), a protease inhibitor (Nelfinavir/ Indinavir) is also added. ${ }^{9}$

Only sixteen respondents (18.8\%) knew all the three drugs out of which 14 were from group III. Sixty eight respondents $(80 \%)$ knew Zidovudine was one of the drugs used in post exposure prophylaxis. Further analysis showed that $92.8 \%$ of group III PGs knew at least one drug used in the PEP regimen while only $33.3 \%$ of dental PGs knew even one drug. Interestingly none of the PGs from either group I or group III knew of all the 3 drugs used in PEP. Six respondents $(7.1 \%)$ gave wrong answers that included various antibiotics and even immunoglobulins.

\section{Availability of drugs}

Drugs for PEP are available in the hospital pharmacy and casualty of our institution round the clock. They are also available at various chemists and pharmacy shops in the city. Thirty six respondents $(42.3 \%)$ knew that the drugs were available but didn't know where? Interestingly, six respondents $(7.1 \%)$ even assumed that the drugs for PEP were not available whereas three respondents $(3.5 \%)$ chose to leave this question unanswered.

\section{Duration of PEP}

PEP is administered for 28 days. ${ }^{9}, 13,14$ Only 26 (30.6\%) knew the duration of post exposure prophylaxis while 42 respondents $(49.4 \%)$ answered wrongly ranging from one dose stat to even up to a year.

\section{Cost of PEP}

A two drug regimen cost around Rs 1300 to Rs 2000 at the time of conducting the study depending on the brand 


\begin{tabular}{lc}
$\begin{array}{lc}\text { Table 2: Distribution of correct responses } \\
\text { to each question }\end{array}$ & $N=85$ \\
\cline { 2 - 2 } \multicolumn{1}{c}{ Question } & Number (\%) \\
\hline Risk of transmission & $19(22.3)$ \\
Identification of high risk fluid & $43(50.6)$ \\
Whom to contact first? & $25(29.4)$ \\
First aid procedure & $20(23.5)$ \\
When to commence PEP? & $43(50.6)$ \\
Drugs used for PEP & $16(18.8)$ \\
Availability of drugs & $36(42.3)$ \\
Duration of PEP & $26(30.6)$ \\
Cost of PEP & $24(28.2)$ \\
\hline
\end{tabular}

and manufacturer. The cost can even go up to Rs 10000 depending on the protease inhibitor added.

Only $24(28.2 \%)$ respondents had an approximate idea while 34 had not attempted an answer to this question. Six of the respondents $(7.1 \%)$ said they had no idea about the cost of drugs for PEP. The wrong answers ranged from Rs 150 to Rs 1 lakh and were given by 21 respondents $(24.7 \%)$.

None of the respondents had answered all questions correctly. The maximum number of correct responses was seven (out of total nine questions) answered by only one respondent. The percentage of correct responses to each question is tabulated below [Table 2].

\section{DISCUSSION}

This study shows a considerable level of ignorance among the respondents regarding the guidelines of PEP. There was also noteworthy difference between the responses of PG residents from various groups, the grouping based on the risk of exposure according to their department. All HCWs should be aware of the risks from occupational exposure so that the delay in seeking advice is minimized.

Risk of transmission of HIV is approximately $0.3 \%$ after a percutaneous exposure to HIV infected blood and $0.09 \%$ after a mucous membrane exposure. ${ }^{6,9,11}$ The risk increases with exposure to a larger quantity of blood as indicated by i) device visibly contaminated with blood, ii) a procedure that involved a needle placed directly in a vein or artery or iii) a deep injury. ${ }^{15}$ In this study only $22 \%$ of the respondents were able to identify the approximate risk. Nearly half of the respondents identified all the high risk fluids but $27 \%$ wrongly considered saliva to be a high risk fluid for the transmission of HIV. Remarkably, $41 \%$ of the dental PG residents considered saliva as a high risk fluid. This may be due to the fact that during the course of certain intraoral procedures saliva may become blood stained and hence the notion among them that saliva is a high risk fluid. Even then the risk is minimal. ${ }^{14,16}$ There has been a report of non-occupational transmission due to contact with bloodcontaminated saliva but there was intimate kissing between sexual partners involved in that case. ${ }^{17}$ However, such an exposure is improbable and perhaps even impossible in health care delivery settings.

The awareness regarding first aid procedure was very low with only $23.5 \%$ of the respondents answering correctly. For percutaneous exposures NACO recommends immediate washing and rinsing the wound and surrounding area with soap and water without scrubbing. '9 Sueezing, bleeding or sucking the wound is not recommended. Though there is no evidence regarding reduction in transmission of HIV by using antiseptics for wound care, ${ }^{14}$ more than half of our respondents happened to think that they were one of the first aid measures. The use of antibiotics is not contraindicated but injection of antiseptics or disinfectants into the wound is not recommended., ${ }^{9,14}$ Nearly half of the respondents were of the opinion that PEP should begin immediately. When a person is exposed to HIV, dendritic cells in the mucosa and skin are the initial targets. Infection of these cells occurs at the site of inoculation during first 24 hours following the exposure of mucosa to cell free virus. Migration of these cells to regional lymph nodes occurs during the next 24-48 hours with subsequent viraemia. ${ }^{18}$ Thus initiation of prophylaxis soon after exposure may prevent systemic infection by limiting proliferation of the virus in the dendritic cell. Though the interval within which PEP should be started for optimal efficiency is unknown and uncertain, studies have indicated that PEP should be initiated as soon as possible and preferably within an hour or two. ${ }^{9,14,19}$ Even if there is a delay PEP should be commenced within 72 hours at the latest. ${ }^{9}$

Zidovudine (AZT), a nucleoside analogue reverse transcriptase inhibitor, when given alone (monotherapy) has been found to reduce the risk of transmission by around 81\%. ${ }^{9,15}$ The experience in HIV infected patients has shown that combination of different antiretroviral agents is superior to monotherapy regimen, so a combination of two or three drug regimen is more beneficial than a single drug regimen. Lamivudine, another nucleoside inhibitor is combined with Zidovudine because the combination has greater antiretroviral activity against many AZT resistant strains. Addition of a protease inhibitor such as Nelfinavir/ Indinavir following a high risk exposure inhibits viral replication at a different stage in replication cycle and thus improving the efficacy of PEP. NACO recommends a basic 2 drug or an expanded 3 drug regimen depending on the nature and risk of exposure. In our study most of the respondents $(80 \%)$ knew about Zidovudine being used in PEP but there was little knowledge about the other two drugs being used. Only 18\% could name all the three drugs 
correctly. These drugs have to be taken for 28 days (4 weeks) as per the guidelines. ${ }^{8,13,14}$ The guidelines are based on the fact that this was the duration when PEP monotherapy was found to be effective. ${ }^{20}$

Although these drugs were available in the pharmacy and even Casualty of our hospitals round the clock, only $42.3 \%$ of respondents were aware of this fact. It is interesting to note that $7.1 \%$ of respondents even believed that the drugs were not at all available. In fact, the drugs for PEP are given free of cost to postgraduates, residents, faculty and staff at our institution. Even otherwise, cost of antiretroviral therapy has reduced drastically in the recent times with 2 drug regimen costing around Rs 1300-2000 and a 3 drug regimen for a minimum of around Rs 5000-6000 depending on the manufacturer. Very few respondents $(28.2 \%)$ in our study had an idea about the cost of PEP. This could lead to them being misled and ignoring the needle stick injuries in view of financial implications.

A similar survey had been conducted by Chogle $e t$ al. in a Mumbai hospital among 39 anaesthetists and 31 surgical residents; only $20 \%$ knew the risk of transmission, only $34 \%$ could identify all the four high risk fluids for transmission of the virus and none of the respondents knew the exact drugs involved in the PEP schedule. ${ }^{18}$ Siwach et al. had reported that $70 \%$ of the 123 residents from various surgical specialities in country's premier institute PGIMER, Chandigarh were not aware of the availability of PEP and most were not aware of the timing of administration. ${ }^{21}$ Another survey among dentists had revealed a good awareness; however it also showed that they did not know the duration, drugs and cost of the therapy. ${ }^{22}$ Our results are very similar to earlier findings by other researchers and similar surveys abroad on surgeons ${ }^{23}$ and anaesthetists. ${ }^{24}$ Our study as well as those cited above demonstrate that doctors and residents are unaware of the PEP guidelines. Low levels of awareness and knowledge of HIV PEP may lead to failure to access PEP, and potential HIV infection.

Every study and its findings should lead to action. This is particularly important when it concerns an important issue like PEP and the population involved is young doctors and future consultants. To achieve this, the overall correct responses for each question and presented these in front of the participants before the end of the Orientation programme. Following this, an expert gave a talk along with multimedia presentation on post-exposure prophylaxis guidelines and also encouraged them to interact and clear their doubts. These guidelines were also printed out and pasted in each ward and commonly noticeable areas in the hospitals. They were also made aware of the hospital policy and protocol in such instances and the free availability of PEP drugs in the hospitals.
However, there were a few limitations in this study. The study did not include the faculty members from various departments and other paramedical health care workers who are at a risk of exposure to similar occupational hazard. Such a study would have been comprehensive and revealed a better picture about the level of awareness in this institution across various cadres of $\mathrm{HCWs}$.

To conclude there is a low level of awareness among postgraduate residents regarding the post exposure prophylaxis for accidental exposure. Awareness should be brought about regarding PEP guidelines among health care workers by frequent training programmes for doctors and residents. The training programmes should include information on occupational health hazards and their prevention, standard precautions, first aid measures, biosafety precautions and post exposure prophylaxis. This should preferably start at the undergraduate level, as medical students in their training will also be at risk. Education should be included in all induction programmes for junior doctors (interns as well as postgraduate residents) at the start of the postings. Each hospital should have an accessible written policy on PEP.

\section{ACKNOWLEGEMENT}

The authors would like to acknowledge with gratitude Dr. C.V. Raghuveer, the former Dean of Kasturba Medical College, Mangalore for granting the permission and extending his full co-operation for the study. They also extend heartfelt thanks to all the postgraduate residents for participating in the study.

\section{REFERENCES}

1. Bailey and Love's Short Practice of Surgery. $24^{\text {th }}$ ed. M/s Arnold, London. 2004. p. 175-182.

2. Richard VS, Kenneth J, Cherian T, Chandy GM. Preventing transmission of blood-borne pathogens to health care workers. Natl Med J India. 2000 Mar-Apr; 13(2):82-85.

3. Park K. Textbook of Preventive and Social Medicine. 17 $7^{\text {th }}$ Ed. M/S Banarasidas Bhanot Publishers, Jabalpur. 2002:259-267.

4. National AIDS Control Organisation. High incidence of AIDS. Available from: http://www.nacoonline.org/NACO_Action/Media_Press_Release/

5. The World Health Organisation. Reducing Risks, Promoting Healthy Life. The World Health Report 2002. Geneva: World Health Organisation; 2002.

6. Bell DM. Occupational risk of human immunodeficiency virus infection in healthcare workers: an overview. Am J Med. 1997 May 19; 102(5B):9-15.

7. Mehta DS. Needle-stick injuries in dental practice. Journal of Indian Dental Association. 2001; 72:196-197.

8. National AIDS Control Organisation. "Management of occupational exposure including postexposure prophylaxis" In: Antiretroviral Therapy Guidelines for HIV infected Adults and Adolescents including Postexposure. 2007. p. 67-90. Available from: http://www.nacoonline.org/ Quick_Links/Publication/Treatment_Care_Support/Operational_ Technical_guidelines_and_policies/Antiretroviral_Therapy_Guidelines_ for_HIV_infected/. 
9. Government of Karnataka, Department Of Health and Family Welfare. Management of occupational exposure and postexposure prophylaxis. In: Participant's Manual for Government and Private doctors on PPTCT Recent Advances in STI and HIV-AIDS Issues. 2005:61-66.

10. Tetali S, Choudhary PL. Occupational exposure to sharps and splash: Risk among health care providers in three tertiary care hospitals in South India. Indian J Occup Environ Med 2006; 10:35-40.

11. Henderson DK, Fahey BJ, Willy M, Schmitt JM, Carey K, Koziol DE et al. Risk for occupational transmission of human immunodeficiency virus type 1 (HIV-1) associated with clinical exposures:A prospective evaluation. Ann Intern Med 1990; 113:740-746.

12. Centre for Disease Control, Atlanta. Recommendations for prevention of HIV transmission in health-care settings. MMWR.1987; 36(suppl no. 2S).

13. National AIDS Control Organisation. Management of Occupational Exposure and Postexposure Prophylaxis. Manual for control of hospital associated infections - Standard Operative Procedures, 2000:67-73.

14. Centers for Diseases Control and Prevention. Public Health Service Guidelines for the management of health-care worker exposures to HIV and recommendations for Postexposure Prophylaxis. MMWR 1998; 47(RR-7):1-33 Available from the URL: www.cdc.gov/mmwr/preview/ mmwrhtml/00052722.htm.

15. Cardo DM, Culver DH, Ciesielski CA, Srivastava PU, Marcus R, Abiteboul $\mathrm{D}$ et al. A case-control study of HIV seroconversion in health care workers after percutaneous exposure. N Engl J Med 1997; 337:1485-90.

16. Fahey BJ, Koziol DE, Banks SM, Henderson DK. Frequency of non parental occupational exposures to blood and body fluids before and after universal precautions training. Am J Med 1991; 90:145-153.
17. Centre for Disease Control. Transmission of HIV possibly associated with exposure of mucous membrane to contaminated blood. MMWR 1997; 46:620-623.

18. Chogle NL, Chogle MN, Divatia J V, Dasgupta D. Awareness of Post exposure prophylaxis guidelines against occupational exposure to HIV in a Mumbai Hospital. Nat Med J India 2002:15:69-71.

19. Sridhar MR, Bhoopathi S, Lodha R, Kabra SK. Standard precautions and post exposure prophylaxis for preventing infections. Indian J Pediatr 2004; 71:617-626.

20. Centre for Disease Control. Case-control study of HIV seroconversion in health-care workers after percutaneous exposure to HIV-infected blood France, United Kingdom, and United States, January 1988-August 1994. MMWR 1995; 44:929-33.

21. Siwach V, Dahiya D, Rao Ch UM, Dhanda R, Sharma A, Minz M. Resident doctors, bloodborne pathogens and universal precautions: are we sitting on a volcano? Natl Med J India 2001; 14:179.

22. Pai V, Sequeira PS, Rao A, Jain A, Kundabala M. A study on awareness of post-exposure prophylaxis guidelines against occupational exposure to HIV among dentists in Mangalore city. J Pierre Fauchard Acad 2006; 20:86-91.

23. Duff SE, Wong CK, May RE. Surgeons' and occupational health departments' awareness of guidelines on post-exposure prophylaxis for staff exposed to HIV: telephone survey. BMJ 1999; 319:162-163.

24. Diprose P, Deakin CD, Smedley J. Ignorance of post-exposure prophylaxis guidelines following HIV needlestick injury may increase the risk of seroconversion. Br J Anaesth 2000; 84:767-770. 